\title{
Influence of internal mammary artery retractor on postoperative patient comfort and quality of life
}

Cenk Eray Yildiz ${ }^{1}$, Cenk Conkbayir ${ }^{2}$, Halil Erkam Tolgay ${ }^{1}$, Mustafa Canikoglu ${ }^{3}$, Kadir Ceviker ${ }^{4}$, Ayfer Acikgoz ${ }^{1}$, Didem Melis Oztas 5 , Omer Ali Sayin ${ }^{5}$, Murat Ugurlucann ${ }^{5}$, Tahsin Beyzadeoglu 6

\author{
${ }^{1}$ Department of Cardiovascular Surgery, Institute of Cardiology, Istanbul University, \\ Istanbul, Turkey \\ ${ }^{2}$ Department of Cardiology, Faculty of Medicine, Near East University, Lefkosa, Cyprus \\ ${ }^{3}$ Department of Cardiovascular Surgery, Kocaeli Derince Education and Research \\ Hospital, Kocaeli, Turkey \\ ${ }^{4}$ Department of Cardiovascular Surgery, Faculty of Medicine, Suleyman Demirel \\ University, Isparta, Turkey \\ ${ }^{5}$ Department of Cardiovascular Surgery, Istanbul Medical Faculty, Istanbul University, \\ Istanbul, Turkey \\ ${ }^{6}$ Department of Orthopedy, Halic University, Istanbul, Turkey
}

Submitted: 2 October 2018

Accepted: 4 November 2018

Arch Med Sci Atheroscler Dis 2018; 3: e174-e178

DOI: https://doi.org/10.5114/amsad.2018.81086

Copyright $\odot 2018$ Termedia \& Banach

\begin{abstract}
Introduction: Patients experience muscle, joint and shoulder pain after heart surgery. We aimed to compare quality of life in 2 groups of patients, one group having an internal mammary artery (IMA) retractor during surgery, the second group undergoing non-coronary heart surgery.

Material and methods: Group 1 was composed of 39 patients receiving an IMA retractor whereas in group 2 there were 29 patients. Patients in groups were compared for postoperative quality of life, shoulder pain, functional status, strength and patient satisfaction.

Results: Visual analog scale (VAS) assessment, pain localization, quality of life SF-36 form, and University of California at Los Angeles (UCLA) functional shoulder scoring were applied in both groups. Mean VAS score in group 1 was significantly higher than in group 2 . Only the vitality measure mean score was not significantly different in SF-36 assessment; however, in group 2 physical function and mental health scale mean scores were higher and the pain scale mean score was lower than in group 1. The total UCLA score and UCLA subgroups of pain, function, active flexion angle and strength revealed a statistically significant difference between groups.

Conclusions: Patients in whom an IMA retractor was not utilized during surgery exhibited better results in physical functions, emotional status, and shoulder pain in the postoperative period.
\end{abstract}

Key words: open heart surgery, internal mammary artery retractor, post-operative pain.

\section{Introduction}

Most open heart surgery procedures are performed through median sternotomy. Median sternotomy is a non-anatomic exposure to the heart and intrathoracic structures. It leads to distension of the ribs, intercostal muscles, and nerves, leading to various complications and especially, to a certain extent, pain. Asymmetric sternal distension during the harvest

\author{
Corresponding author: \\ Assoc. Prof. Cenk Eray Yildiz \\ Department of \\ Cardiovascular Surgery \\ Institute of Cardiology \\ Istanbul University \\ Istanbul, Turkey \\ Phone: +90 5308251122 \\ E-mail: ceyildiz@hotmail.com, \\ muratugurlucan@yahoo.com
}


of the internal mammary artery (IMA) is on the other hand even more brutal than symmetric sternal spread.

There is definite need for new techniques to facilitate the recovery of patients following open heart surgery and to improve the quality of their lives. The literature indicates a $2-38 \%$ rate of brachial plexus injury during median sternotomy [1-5] and depending on the damage to the brachial plexus and recovery may reach beyond 6 months following surgery [1]. From that point of view, harvest of the IMA may be reassessed and various other methods may be investigated. As a result, both the comfort and life quality of the patient would be enhanced and loss of labor force in the early and late terms would be prevented.

This study aimed to research the shoulder pain, quality and comfort of life of patients undergoing open heart surgery with comparative analysis of two groups of patients: having an internal mammary artery retractor utilized or only a regular sternal retractor during surgery.

\section{Material and methods}

A total of 68 consecutive patients included in this study were divided into two groups. Group 1 comprised 39 patients in whom an IMA retractor was used during their surgery. There were 29 patients in group 2 and the IMA retractor was not required in their surgery. The operations of the patients included valvular heart diseases, diseases of the ascending aorta and the aortic arch, and congenital heart defects in group 2. Patients were informed about the procedures and research prior to their interventions and were included in the study following their consent. Patients with shoulder joint problems, a history of prior cardiac or thoracic operations, genetic, autoimmunologic and/or rheumatologic diseases were excluded from the study.

\section{Parameters}

The following parameters were investigated:

1. Visual Analog Scale (VAS) assessment

2. Pain localization

3. Quality of life: SF-36 form

4. UCLA (University of California at Los Angeles) functional shoulder scoring

\section{Visual Analog Scale (VAS) assessment}

The Visual Analog Scale is used for numerical conversion of values that cannot be measured quantitatively. Patients are requested to indicate their situation on a $100 \mathrm{~mm}$ line with one end marked as no pain and the opposite end as severe pain. The distance measured from the no pain mark to the patient's point is accepted as the numeric pain score of the patient.

\section{Pain localization}

The patient is asked to show the localization of the pain at the shoulder region whether it is on the right or left side, proximal or distal region of the clavicle, anterior or posterior part of the deltoid muscle, lateral to the pectoral or deltoid muscles or at the scapula. In addition, the painkillers are recorded if the patient received any.

\section{Quality of life}

The patients were asked to fill in the SF-36 questionnaire that is composed of 36 questions giving an idea about the quality of life and general health status, 4 weeks after the operations. The questionnaire contains queries about physical function, physical role compromise, pain, general health, social function, emotional role compromise and mental health. The total score of the questionnaire is 100 and higher scores indicate better health.

\section{UCLA (University of California at Los Angeles) functional shoulder score}

The patients were assessed at the end of the first month follow-up. The UCLA shoulder score has 35 points and comprises pain, function, active flexion, range of motion, strength and patient satisfaction. Total UCLA score is classified as excellent (33-35), good (28-32), moderate (23-27) and poor (<23). Pain (10 points), function (10 points), and patient satisfaction (5 points) sections are subjective responses of the patients to the parameters and make up $70 \%$ of the total score. Pain is assessed usually in conjunction with function. Range of motion (5 points) and strength (5 points) are measurable parameters and make up the $30 \%$ of the total score. As a result, since UCLA scoring contains subjective parameters, it increases the correlation with the SF-36 quality of life questionnaire.

\section{Statistical analysis}

Statistical analysis was performed with the computer software SPSS 13.0 (SPSS Inc. Chicago, Illinois, USA) for Windows by a professional statistician. Data are expressed as mean with standard deviation. The statistics of descriptive data are presented as frequency, ratio, mean \pm standard deviation. The distribution of the data was tested with the Kolmogorov-Smirnov test. Non-parametric data were analyzed with the Mann-Whitney $U$ test and parametric variables with the $t$ test. Proportional variables were analyzed with Yates's chi-squared $\left(\chi^{2}\right)$ test and Fisher's exact test. Descriptive variables were analyzed with Spearman correlation and variables were classified with Pearson correlation analyses. A p-value of less than 0.05 was considered significant. 
Cenk Eray Yildiz, Cenk Conkbayir, Halil Erkam Tolgay, Mustafa Canikoglu, Kadir Ceviker, Ayfer Acikgoz, Didem Melis Oztas, Omer Ali Sayin, Murat Ugurlucan, Tahsin Beyzadeoglu

\section{Results}

Mean age of the patients was $61.03 \pm 10.03$ years in group 1 and $53.37 \pm 14.95$ years in group 2 . The age of the patients in group 1 was statistically higher than in group $2(p=0.039)$ (Table I). The mean age of the male patients did not differ significantly between the two groups ( $p=0.987$ ); however, female patients were significantly older in group $1(p=0.033)$. In group $1,74.4 \%$ of the patients were male and $25.6 \%$ were female, whereas $35.7 \%$ were male and $64.3 \%$ female in group 2 ( $p=0.02$ ). The prevalence of diabetes mellitus was $48.7 \%$ in group 1 and $21.4 \%$ in group 2 ( $p=$ $0.023)$. Other factors including hypertension, cigarette smoking, and obesity did not differ significantly between the two groups.

When considering the postoperative pain status of the patients, only on the postoperative first day was there no statistically significant difference; however, the percentage of pain occurrence was significantly higher in IMA retractor group 1 on the postoperative second, third and fourth days. None of the patients in group 2 complained of severe debilitating pain on the third and fourth postoperative days. The mean VAS scores were found to be higher in group 1 than in group 2 on all days (Table II). The VAS assessment revealed no statistically significant difference between the two groups in vitality scale mean scores. On the other hand, the mean scores of physical condition, physical role, general health, social function, emotional role and mental health were found to be higher and the pain mean score was found to be lower in group 2 (Table III).

The UCLA functional shoulder score, the total UCLA score and subgroups of pain, function, active flexion angle, and power were statistically significantly higher in group 2, whereas there was no statistically significant difference between the two groups in patient satisfaction (Table III).

Since the percentages of men and women in both groups were not identical, the results were assessed according to sex. Although the VAS scores did not differ significantly between male and female patients, the mean scores in group 1 were higher on all days than in group 2 . The vitality scale score in the SF-36 quality of life questionnaire did not differ significantly between men in the two groups; however, it was significantly higher among women in group 2 $(p=0.012)$. When UCLA functional shoulder score was adapted to sex, except for patient satisfaction, there was a statistically significant difference between the genders in all UCLA parameters.

\section{Discussion}

The internal mammary artery has vital importance during coronary revascularization. The actual aim of coronary artery bypass graft surgery (CABG) is the anastomosis of the IMA to the left anterior descending artery and none of the medical technologic advances has beaten the patency of this bypass [6]. However, following CABG patients may experience severe pain which compro-

Table I. Patient demographics

\begin{tabular}{|lccc|}
\hline Parameter & Group 1 $(n=39)$ & Group 2 $(n=28)$ & $P$-value \\
\hline Age, mean \pm SD [years] & $61.03 \pm 10.03$ & $53.37 \pm 14.95$ & 0.039 \\
\hline Gender, F/M & $29 / 10$ & $10 / 18$ & 0.002 \\
\hline
\end{tabular}

Table II. Postoperative pain scores and VAS score assessment

\begin{tabular}{|c|c|c|c|}
\hline Day & Group $1(n=39)$ & Group $2(n=28)$ & $P$-value \\
\hline \multicolumn{4}{|c|}{ Feeling pain/no pain $(n)$ : } \\
\hline Postop. $1^{\text {st }}$ & $37 / 2$ & $28 / 0$ & 0.506 \\
\hline Postop. $2^{\text {nd }}$ & $38 / 1$ & $12 / 16$ & 0.001 \\
\hline Postop. $3^{\text {rd }}$ & $36 / 3$ & $0 / 28$ & 0.001 \\
\hline Postop. $4^{\text {th }}$ & $35 / 4$ & $0 / 28$ & 0.001 \\
\hline \multicolumn{4}{|c|}{ VAS scores (mean \pm SD): } \\
\hline Postop. $1^{\text {st }}$ & $8.95 \pm 1.73$ & $5.00 \pm 1.54$ & 0.001 \\
\hline Postop. $2^{\text {nd }}$ & $7.28 \pm 1.73$ & $1.29 \pm 1.78$ & 0.001 \\
\hline Postop. $3^{\text {rd }}$ & $5.59 \pm 1.87$ & $0.00 \pm 0.00$ & 0.001 \\
\hline Postop. $4^{\text {th }}$ & $3.21 \pm 1.64$ & $0.00 \pm 0.00$ & 0.001 \\
\hline
\end{tabular}


Table III. SF-36 and UCLA score assessments

\begin{tabular}{|lcll|}
\hline Score & $\begin{array}{c}\text { Group } 1(n=39) \\
\text { Mean } \pm \text { SD }\end{array}$ & $\begin{array}{c}\text { Group } 2(n=28) \\
\text { Mean } \pm \text { SD }\end{array}$ & $P$-value \\
\hline SF-36: & $50.77 \pm 15.88$ & $87.32 \pm 6.31$ & 0.001 \\
\hline Physical function & $7.05 \pm 23.61$ & $96.43 \pm 13.11$ & 0.001 \\
\hline Physical role & $35.13 \pm 16.84$ & $15.36 \pm 6.93$ & 0.001 \\
\hline Pain & $52.56 \pm 5.48$ & $49.46 \pm 4.16$ & 0.014 \\
\hline General health & $52.82 \pm 8.34$ & $55.54 \pm 5.15$ & 0.132 \\
\hline Vitality & $41.67 \pm 9.22$ & $49.55 \pm 4.14$ & 0.001 \\
\hline Social function & $11.11 \pm 30.91$ & $97.62 \pm 8.74$ & 0.001 \\
\hline Emotional role & $52.82 \pm 7.58$ & $62.43 \pm 6.74$ & 0.001 \\
\hline Mental health & & 0.001 \\
\hline UCLA: & $5.49 \pm 1.88$ & $8.50 \pm 0.88$ & 0.001 \\
\hline Pain & $4.23 \pm 1.65$ & $9.71 \pm 0.71$ & 0.001 \\
\hline Function & $3.92 \pm 0.58$ & $5.00 \pm 0.00$ & 0.001 \\
\hline Active flexion range & $4.00 \pm 0.61$ & $5.00 \pm 0.00$ & 1.000 \\
\hline Strength & $5.00 \pm 0.00$ & $5.00 \pm 0.00$ & 0.001 \\
\hline Patient satisfaction & $22.46 \pm 3.76$ & $33.21 \pm 1.26$ & \\
\hline Total UCLA score & & \\
\hline
\end{tabular}

mises the quality of life of the patients after the surgery as a consequence of IMA harvest.

Despite advances in minimally invasive and endoscopic techniques and even the use of a robot, median sternotomy is still the most common approach for cardiac procedures. Midline spread of the sternum and bilateral retraction is non-anatomic and causes damage to the adjacent and remote muscles, ribs, and nerves to a certain extent. The internal mammary artery is usually harvested with upward displacement of one side of sternum following retraction, and this maneuver affects even more adversely the soft and hard tissues of the chest. In a study on pigs, the IMA was harvested using an ultrasonic aspirator through a small incision [7]. In recent years with the advances in technology, it is sometimes harvested with the help of a robot or endoscopic instruments through intercostal spaces or subxyphoid mini-incisions [8].

Apart from bones and muscles, nerves and especially the brachial plexus seem to be the most important structures responsible postoperatively for short- and long-term debilitating symptoms ranging from severe pain to disabilities. The issue has been investigated previously by different authors [1-5, 7-11]; however, apart from the current study, none has researched postoperative pain and related symptoms with objective parameters and established scales.
The brachial plexus emerges from the lower four cervical nerves and first thoracic nerve. The plexus passes through the cervicoaxillary canal in the neck and through the first rib reached to the axilla. It innervates the upper limb, some of the neck as well as shoulder muscles [12]. Hence, it is prone to a certain degree of trauma during open heart surgery probably due to sternal retraction.

Injury to the brachial plexus is more common than it is reported. It is usually underestimated because in most cases injury is not severe and usually transient [9]. It is a neurologic problem which affects mostly the eighth cervical and first thoracic vertebrae [1]. Although various factors have been implicated in the etiology [1], the most important among all seems to be patient-related anatomical variations, patient positioning, and trauma during surgery. Especially fractures of the first rib are strongly related to brachial plexus injury [10] due to the vicinity of the nerve fibers [12]. Especially during harvest of the IMA, asymmetric traction of the sternal halves worsens the integrity of the brachial plexus more than any other maneuvers [9]. In a study, Vahl et al. [5] reported 10\% brachial plexus injury in patients undergoing CABG using the IMA, but $1 \%$ injury if no IMA was prepared for CABG. On the other hand, the findings of Canbaz et al. [10] are contradictory to many others in the literature and the authors stated that they did not 
find an association between IMA harvest and development of nerve injuries.

Initial symptoms secondary to the injured brachial plexus are pain, and motor and sensory disturbances at the affected upper limb [1] from the scapula and shoulder to the hand. Symptoms may range between temporary numbness to severe disability of the upper limb with decreased ability to use the arm. Treatment is usually palliative and with various physiotherapeutic methods.

Despite a very promising CABG, brachial plexus injury and its consequences are very important and may affect the whole life of the patients. and various measures have been proposed to prevent or at least minimize the injury to the brachial plexus. In a study to prevent brachial plexus injury, extending the arms upwards aided in lesser trauma [11]. Chong et al. [9] and Scott et al. [11] propose a 'hands-up' position rather than 'arms at the side' with the hypothesis that it reduces the stress on the brachial plexus during asymmetric sternal traction during IMA harvest as well as ulnar nerve compression [9] when the arms are at the sides. Additional maneuvers such as precise midline median sternotomy, lower placement of the sternal retractor, avoidance of constant and excessive traction of the sternal halves, and minimization of asymmetric sternal traction especially during IMA harvest as well as cautious usage of an asymmetric traction retractor are vitally important to prevent brachial plexus injury. Early postoperative neurologic assessment is crucial to detect neurologic damage and prompt therapeutic action [1].

In conclusion, in this study we investigated the quality of life of two sets of patients. In one group the IMA retractor was utilized and the other was composed of patients requiring non-coronary surgery, with different pain scoring systems and quality of life scales. Patient comfort and the quality of life of patients were significantly enhanced following open heart surgery in the group where an IMA retractor was not used during surgery according to the results of our study. As a result, not only the comfort of the surgeon during surgery but also postoperative patient benefits should be taken into account during cardiac surgery. When possible, in order to prevent shoulder and arm pain, an IMA retractor should be avoided or at least should be extended as minimally as possible. Keeping the fact in mind and knowing none of the retractors to be very safe, further measures are required in order to design and produce newer instruments creating minimal extension; however, better exposure during the IMA harvest needs to be investigated by biomedical engineers and heart surgeons.

\section{Conflict of interest}

The authors declare no conflict of interest.
References

1. Unlu Y, Velioglu Y, Kocak H, Becit N, Ceviz M. Brachial plexus injury following median sternotomy. Interact Cardiovasc Thorac Surg 2007; 6: 235-7.

2. Hanson MR, Breuer AC, Furlan AJ, et al. Mechanism and frequency of brachial plexus injury in open heart-surgery: a prospective analysis. Ann Thorac Surg 1983; 36: 675-9.

3. Marganitt B, Shemesh Y, Golan M, Lin E, Engel J. Subclinical brachial plexopathy following median sternotomy. Orthop Rev 1986; 15: 305-10.

4. Sotaniemi KA. Brachial plexus lesion complicating sternotomy. J Neurol Neurosurg Psychiatry 1982; 45: 568.

5. Vahl CF, Carl I, Muller-Vahl H, Struck E. Brachial plexus injury after cardiac surgery, the role of internal mammary artery preparation: a prospective study on 1000 consecutive patients. J Thorac Cardiovasc Surg 1991; 102: 724-9.

6. Hulusi M, Basaran M, Ugurlucan M, Kocailik A, Basaran EK. Coronary artery bypass grafting with Y-saphenous vein grafts. Angiology 2009; 60: 668-75.

7. Shimizu Y, Watanabe G, Tomita S, Matsumato I, Lino K. A novel technique for harvesting the internal thoracic artery: linear harvesting technique using an ultrasonic surgical aspirator. Interact Cardiovasc Thorac Surg 2011; 12: 998-1001.

8. Takata M, Watanabe G, Ushijima T, Ishikawa N. A novel internal thoracic arter harvesting technique via subxiphioid approach- for the least invasive coronary artery baypas grafting. Interact Cardiovasc Thorac Surg 2009; 9: 891-2.

9. Chong AY, Clarke CE, Dimitri WR, Lip GYH. Brachial plexus injury as an unusual complication of coronary artery bypass graft surgery. Postgrad Med I 2003; 79: 84-86.

10. Canbaz S, Turgut N, Halici U, Sunar H, Balci K, Duran E. Brachial plexus injury during open heart surgery-controlled prospective study. Thorac Cardiovasc Surg 2005; 53: 295-9.

11. Jellish WS, Blakeman B, Warf P, Slogoff S. Hands-up positioning during asymmetric strenal retraction for internal mammary artery harvest: a possible method to reduce brachial plexus injury. Anesth Analg 1997; 84: 260-5.

12. https://en.wikipedia.org/wiki/Brachial_plexus 